\title{
Effectiveness of Amniotic Membrane with Coronally Advanced Flap in the Treatment of Gingival Recession in Adult Patients: A Systematic Review
}

\author{
Ankita A Katkurwar ${ }^{1}$, Swapna A Mahale ${ }^{2}$
}

\begin{abstract}
Aim and objective: To evaluate the effectiveness of amnion membrane on the clinical parameters when used in the treatment of Millers Class I and Class II gingival recession in chronic periodontitis patients along with coronally advanced flap (CAF).

Data resources: Four databases MEDLINE (by PubMed), Cochrane database, EBSCO, and Google Scholar were explored to identify the studies in English up to April 2020. An additional hand search of relevant journals was also done. Two independent reviewers screened the retrieved articles using the particular inclusion criteria. Randomized control trials (RCTs) evaluating the effectiveness of amnion membrane with CAF in treatment of Millers Class I and Class II gingival recession in chronic periodontitis patients were included in the study. Outcome variables examined were recession width (RW), recession depth (RD), clinical attachment level (CAL), keratinized width of gingiva (KWG), probing pocket depth (PD), and gingival thickness (GT). Data were analyzed using Revman5.3 software. The mean differences and $95 \%$ confidence interval were used to illustrate the estimate of effect size.

Study selection: Seven relevant articles were recognized for data procurement. One hundred and twenty patients with 244 gingival recession sites in total with an age range between 18 years and 55 years of participants were selected. There is an equal effect in both the groups for the $\mathrm{RD}$ reduction. For RW reduction, the result was in the favor of amnion membrane with CAF group, whereas for CAL gain, PD reduction, KWG gain, and GT gain results favored the different biomaterial other than amnion membrane but no statistical significant difference was found. Conclusion: Within the limitation of the study, it seems that the amnion membrane can be used successfully along with CAF to treat the gingival recession.

Keywords: Amnion membrane, Chronic periodontitis, Coronally advanced flap, Gingival recession, Placental membrane, Root coverage, Systematic review.

International Journal of Experimental Dental Science (2021): 10.5005/jp-journals-10029-1223
\end{abstract}

\section{INTRODUCTION}

"Gingival recession (GR) is the change in the position of the marginal part of the gums apically to the cementoenamel junction (CEJ) with denudation of the root surface". It is induced due to pathological, anatomical, and traumatic factors. ${ }^{1}$ It is responsible for esthetic concern, difficulty in oral hygiene maintenance, loss of the tooth, root sensitivity, and root caries. ${ }^{2}$ Gingival recession is seen in subjects with periodontal disease as well as with good oral hygiene. ${ }^{3}$ The gingival recession of $1 \mathrm{~mm}$ or more in one or more sites is seen in $50 \%$ of the population. ${ }^{4}$

For the root coverage of single or multiple recessions, several newer and advanced techniques of periodontal plastic surgery have been propounded. Coronally advanced flap (CAF) is a commonly used mucogingival procedure where the gingival flap is shifted coronally over the exposed root surface. Evidence suggests that CAF is a predictable as well as an effective technique since the results of root coverage are favorable with good color blending, restores the original morphology of the treated gingival site postoperatively. ${ }^{5}$ The procedure is convenient and less invasive since no graft is harvested when treated with CAF alone. However, it was reported that the result of root coverage is not stable in a long-term follow-up. The root coverage was $89 \%$ at 1 month and declined to $58.8 \%$ at a 6 -month postoperative follow-up. ${ }^{6}$ In CAF, healing occurs by repair (forming long junctional epithelium) and not by regeneration. Thus, it is often combined with many biological factors or regenerative materials following the technique based on the GTR principle.

\begin{abstract}
1,2 Department of Periodontology, MGVS KBH Dental College and Hospital, Nashik, Maharashtra, India

Corresponding Author: Ankita A Katkurwar, Department of Periodontology, MGVS KBH Dental College and Hospital, Nashik, Maharashtra, India, Phone: +91 9309199790, e-mail:katkurwarankita@ gmail.com

How to cite this article: Katkurwar AA, Mahale SA. Effectiveness of Amniotic Membrane with Coronally Advanced Flap in the Treatment of Gingival Recession in Adult Patients: A Systematic Review. Int J Experiment Dent Sci 2021;10(1):25-35.
\end{abstract}

Source of support: Nil

Conflict of interest: None

The gold standard technique for the treatment of gingival recession is coronally advanced flap (CAF) along with connective tissue graft (CTG). ${ }^{7}$ But the need for donor tissue that results in a second surgical site is the main disadvantage of the CTG technique. It also causes patient discomfort, postoperative pain, and a large amount of tissue is needed to treat multiple recessions. ${ }^{8}$ Thus, alternative grafts and biomaterials recommended are autologous plasma, ${ }^{3}$ enamel matrix derivatives (EMDs), ${ }^{9}$ acellular dermal matrices, ${ }^{10}$ chorion membrane, ${ }^{11}$ amnion membrane, ${ }^{12}$ and collagen membrane. $^{13}$

Amnion membrane was first used by Davis in $1910 .{ }^{14}$ It is a tough, thin, transparent, avascular composite allograft membrane 
of different layers such as thin epithelium, a thick basement membrane, and an avascular mesenchyme pieced of collagen mainly. ${ }^{15}$ Owing to the presence of various growth factors like epidermal growth factor (EGF), fibroblast growth factor (FGF), hepatocyte growth factor (HGF), transforming growth factor-a (TGF- $\alpha$ ), transforming growth factor- $\beta$ (TGF- $\beta$ ), and keratinocyte growth factor (KGF), it induces angiogenesis, reduces the pain, and promotes epithelialization and extracellular matrix deposition. It has a variety of specialized proteins like proteoglycan, fibronectin, laminin, and collagen type I, IV, V, and VII. It also possess various biological properties such as anti-inflammatory, antiviral, antimicrobial, anti-scarring, and immunomodulatory. ${ }^{16}$ Thus, a third generation bioresorable amniotic membrane provides the structural as well as anatomical arrangement of regenerated tissues, boost the gingival wound healing and augments a rich source of stem cell thus advocated in various periodontal plastic surgical procedures. $^{17}$

Thus, this systematic review aimed to evaluate the effectiveness of amnion membrane in comparison with different biomaterials when used with CAF for root coverage in chronic periodontitis patients.

\section{Materials and Methods}

\section{Protocol and Registration}

To avoid any unintentional reiteration of the review on this topic, registration of the review protocol was done at an international database of prospectively registered systematic reviews PROSPERO (CRD42020175541).We composed the review as per Preferred Reporting Items for Systematic Review and Meta-analysis (PRISMA) guidelines $^{18,19}$ and also ensued PRISMA statement and Cochrane Handbook for Systematic Reviews of Interventions. ${ }^{20,21}$ Our review question was: "What is the effectiveness of amnion membrane with Coronally Advanced Flap in the treatment of gingival recession in adult patients".

\section{Focused PICOS Question}

The following PICOS model was employed for this review: $\mathrm{P}$-Chronic periodontitis patients with Millers Class I or Class II localized gingival recession.

I-Interventions being evaluated was the surgical technique of CAF in combination with amnion membrane.

$\mathrm{C}$-Comparison was done with the surgical technique of CAF in combination with different biomaterials other than amnion membrane.

O-Different type of outcome being measured were

- Primary outcome:

- Gingival recession depth (RD)

- Gingival recession width (RW)

- Width of keratinized gingiva (KWD)

- Secondary outcomes:

- Probing pocket depth (PD)

- Gingival biotype (GT)

- Clinical attachment level (CAL)

In the included studies, all these clinical parameters were evaluated for a period of a minimum 6-month postoperatively.

$\mathrm{S}$-Studies searched were randomized control clinical trials (RCTs), published only in the English language and restricted to human gingival recession defect.

\section{Search Strategy}

We executed a comprehensive literature search up to April 2020. All randomized control clinical trials done on the human gingival tissues were scouted in four databases MEDLINE (by PubMed), EBSCO, Cochrane Database, and Google Scholar. Journals like Journal of Periodontology, Journal of Clinical Periodontology, Journal of Periodontal Research, and International Journal of Periodontics and Restorative Dentistry were hand searched to recover additional articles. Even the references list of relevant articles were appraised.

The electronic search included the following terms: ("amnion membrane" OR "placental membrane" OR "amnion") AND ("coronally advanced flap") AND ("Class I" OR "Class II") AND ("gingival recessions" OR "root coverage") AND ("randomized controlled trial").

\section{Inclusion and Exclusion Criteria \\ Inclusion Criteria}

- Subjects who are systemically healthy having age $>18$ years

- Patients diagnosed with chronic periodontitis having a defect of Miller's Class I or Class II gingival recessions.

- Patients who can maintain good oral hygiene.

- Both males and females subjects were included.

- Patients who are willing to take part in the study and report for regular follow-up.

\section{Exclusion Criteria}

- Subjects having a habit of smoking.

- Female patients who are lactating or pregnant during the study period.

- Patients treated for periodontal disease in the last 6 months

- Subjects who fail to maintain good oral hygiene.

\section{Screening and Data Extraction}

Two reviewers independently screened the title and abstract of the initially identified studies. Any duplication or articles that do not meet inclusion criteria were exempted. Full-text copy for all eligible articles was obtained and two reviewers assessed them separately to determine whether they qualify the inclusion norms. Any disagreement was resolved by discussion. Articles were excluded if they were not as per the inclusion norms. The reasons for exclusion were recited. In a Microsoft excel sheet, the data of the included studies were extracted.

For the meta-analysis, the clinical parameters (i.e., RD, RW, $\mathrm{KTW}, \mathrm{PD}, \mathrm{CAL}$, and GT) were collected from the included studies. If the included studies did not disclose the mean difference and standard deviation of the clinical parameters assessed (difference between follow-up and baseline), a further calculation of the mean difference would be requested. For each comparison, the initial step was to calculate the intragroup mean difference between baseline and follow-up.

Intragroup mean difference: ${ }^{22}$

$\delta$ Mean $_{\text {ctrl }}=$ (Follow-up data of control group) - (Baseline data of control group)

$\delta$ Mean $_{\text {test }}=($ Follow-up data of test group $)-($ Baseline data of test group)

The second step was to calculate the intergroup difference by: $\Delta$ Mean $=\delta$ Mean $_{\text {ctrl }}-\delta$ Mean $_{\text {test }}$ 


\section{Outcome Measurements}

\section{Primary Outcome}

- Change in RD was reported as a reduction in recession at the 6-month follow-up evaluation (RD was measured at the midbuccal from CEJ to the gingival margin).

- Change in RW was reported as a reduction in RW at the 6-month follow-up evaluation (RW was measured at the buccal surface at the level of the CEJ from the mesial most to the distal-most of the gingiva).

- Change in KTW was reported as gain in KTW at the 6-month follow-up evaluation (KTW was measured as the distance from the mucogingival junction to the free gingival margin).

\section{Secondary Outcome}

- Change in PD was reported as a reduction in PD at the 6-month follow-up evaluation (PD was measured from margin of free gingiva to periodontal pocket).

- Change in CAL was reported as a reduction in CAL at the 6-month follow-up evaluation (CAL was referred to as the distance from the CEJ to the most apical part of the sulcus).

- Change in GT was reported as gain in GT at the 6-month follow-up evaluation (GT was measured $3 \mathrm{~mm}$ below the gingival margin at the level of attached gingiva).

\section{Risk of Bias}

Two investigators appraised the quality of selected studies separately using the risk of bias assessment tool (The Cochrane collaboration's tool). ${ }^{20}$ If any debate over a review, then it was settled by conversation. By using the risk of bias assessment tool, the studies were categorized as a high, low, or unclear risk of bias. After the quality assessment, the included studies were graded into (1) low risk: when all criteria were met or one criterion was unclear/ not met; (2) moderate risk: when two criteria were unclear/not met; (3) high risk: when more than two criteria were not met. As per the Cochrane handbook, Chi-square and Higgins index $\left(I^{2}\right)$ were used to decide the heterogeneity. ${ }^{20}$

\section{Statistical Analysis}

For the meta-analysis, Revman5.3 (Review Manager Version 5.3; The Cochrane Collaboration, Copenhagen, Denmark) software ${ }^{21}$ was employed for the included studies. The continuous data (including RD, RW, KTW, PD, CAL, and GT) were estimated as mean difference (MD) and 95\% confidence interval $(\mathrm{Cl})$, with $p<0.05$ being statistically significant. The fixed-effect model was applied when the heterogeneity between the studies was low $(p \geq 0.10$, $\left.P^{2} \leq 50 \%\right)$ and when heterogeneity was high $\left(p<0.10, I^{2}>50 \%\right)$, the random effect models were applied for meta-analysis. The heterogeneity across studies in RD, RW, WKG, CAL, PD, and GT were correlated through subgroup analysis. The results of meta-analysis were represented in the forest plot.

\section{Results \\ Study Selection}

Two hundred and ninety studies were identified after the initial electronic search and only two studies were obtained by hand search. After duplicate removal, 121 records were screened for title and abstract, 111 articles were eliminated, and remaining 10 articles were scrutinized for full text. ${ }^{5,23-31}$ Three articles were excluded after the full text evaluation ${ }^{29-31}$ because one study reported insufficient follow-up period and even bone graft (DFDBA) was used along with amnion membrane ${ }^{29}$ and in other two studies no biomaterials were utilized along with CAF for control group. ${ }^{30,31}$ Finally seven studies were selected for data extraction. ${ }^{5,23-28}$ The selection process was outlined in the PRISMA flowchart (Flowchart 1).

\section{Study Characteristic}

Total 120 patients with 244 sites with either Millers Class I or Class II gingival recession were included except in Rehan et al.'s ${ }^{5}$ study where only Millers Class I gingival recession sites were enrolled. A maximum of 30 patients participated in Jain et al.'s ${ }^{27}$ study, whereas a minimum of 10 patients participated in Rehan et al.' $s^{5}$ study. Ghahroudi et al.'s $\mathrm{s}^{23}$ study included a maximum of 71 sites, whereas Rehan et al.'s $\mathrm{s}^{5}$ study included a minimum of 10 sites. Three articles ${ }^{24,25,28}$ were according to a split-mouth study design and four articles $5,23,26,27$ followed a parallel study design. The age

Flowchart 1: Literature search PRISMA flow diagram

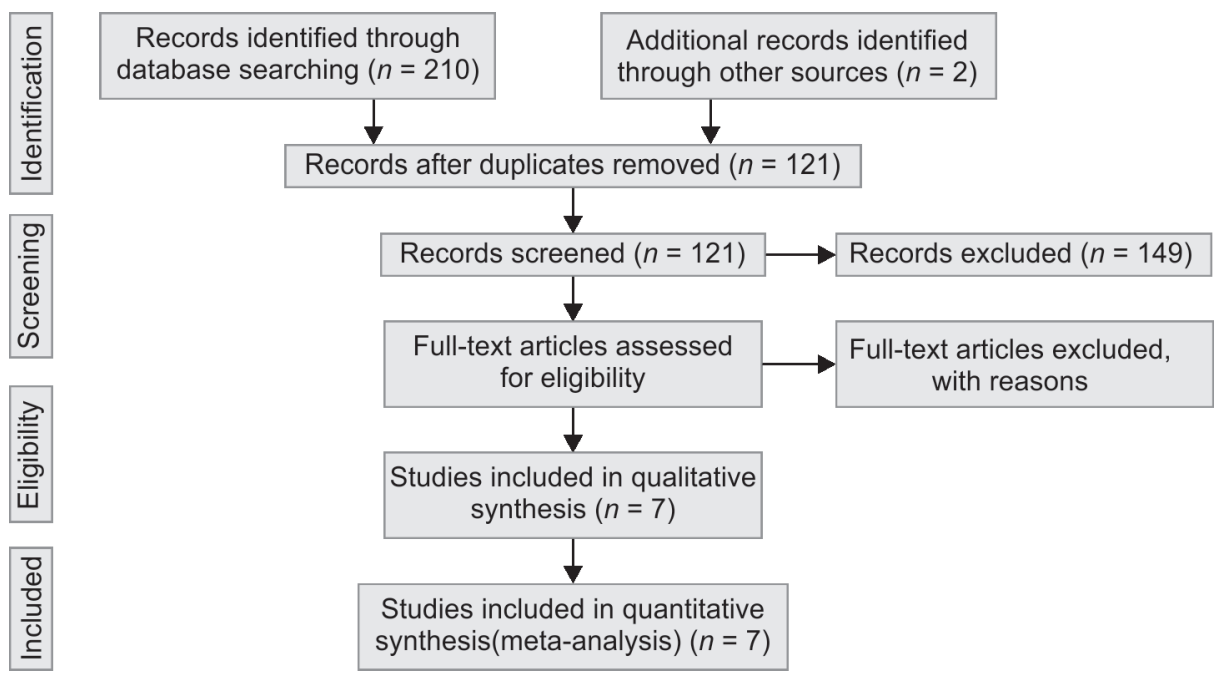


range of the participants was between 18 years and 55 years in all the studies except in the study of Agarwal et al. ${ }^{26}$ age was not mentioned. The mean age of participants was intimated in the study of Chakraborthy et al. ${ }^{24}$ and Lafzi et al. ${ }^{25}$ Five studies ${ }^{5,23,26-28}$ described gender distribution of patients and in one study only male patients were included. ${ }^{5}$ In all the included studies minimum follow-up was of 6 months. Maximum of 18-month follow-up was mentioned in Rehan et al.'s study. ${ }^{5}$ Two out of seven included studies were conducted in $\operatorname{Iran}^{23,25}$ and the other five studies in India. In Table 1, the characteristics of the included articles were illustrated and the extracted data were outlined in Table 2.

\section{Quality of Studies}

All the seven articles mentioned sequence generation: two articles used a flip a coin method, ${ }^{23,25}$ one used chit method, ${ }^{26}$ one lottery method, ${ }^{27}$ and the remaining three articles ${ }^{23,24,28}$ did not explain the method of random sequence generation. Out of seven included articles, six articles ${ }^{5,23-27}$ did not account allocation concealment, whereas one article $^{28}$ intimated it. Since it is a surgical procedure, it was not possible to be blind to the patients. In Rehan et al.'s ${ }^{5}$ study, only patients were blinded whereas in Lafzi et al.'s ${ }^{25}$ study only assessors were blind. In one article, ${ }^{23}$ the patients and the assessors were both were blind while in the remaining four ${ }^{24,26-28}$ articles it was unclear. All the studies had complete follow-up reports. None of the study stated selective reporting and other biases. On evaluation, one article ${ }^{23}$ was claimed as low risk, two articles ${ }^{5,25}$ as moderate risk (when two criteria were not met or unclear), and four articles ${ }^{24,26-28}$ as high risk (when three or four criteria were not met or unclear). Figure 1 summarizes the quality assessment of the included studies.

\section{Outcome}

\section{RD Reduction}

Seven studies ${ }^{5,23-28}$ were included in the meta-analysis. A model employed was a fixed-effects model $\left(I^{2}=41 \%\right)$. According to the result obtained the use of amnion membrane and other biomaterials along with $C A F$ caused an equal reduction in $\mathrm{RD}$ in the treatment of gingival recessions (Fig. 2A). No significant difference was found for CTG, PRF, collagen, and chorion group as per subgroup analysis.

\section{RW Reduction}

The meta-analysis for RW reduction was performed on five studies. Two studies ${ }^{27,28}$ were excluded for their incomplete data. A model employed was a random-effects model $\left(I^{2}=55 \%\right)$. The results manifested that the use of amnion membrane along with CAF causes a reduction in $\mathrm{RW}$ in the treatment of gingival recessions (Fig. 2B). No significant difference was found for CTG, PRF, and chorion group according to the subgroup analysis.

\section{Keratinized Width of Gingiva Gain}

The meta-analysis was performed on five studies for keratinized width of gingiva (KWG) gain. Two articles ${ }^{23,28}$ did not provide specific data thus were excluded from the meta-analysis. A model employed $\left(I^{2}=39 \%\right)$ was a fixed-effects model. The results manifested that the use of different biomaterial groups (other than amnion membrane) caused a reduction in KWG when combined with CAF in the treatment of gingival recessions (Fig. 2C). As per the results of the subgroup analysis, only chorion membrane could significantly improve the KTW, with an MD of $0.09 \mathrm{~mm}(95 \% \mathrm{Cl}$ : $0.07-0.26 \mathrm{~mm} ; p=0.04)$. A significant difference was not found in the subgroup of CTG and PRF groups.

\section{PD Reduction}

The meta-analysis for PD reduction was performed on four studies. Three studies ${ }^{23,24,27}$ were excluded for its incomplete data. A model employed was fixed-effects model $\left(I^{2}=0 \%\right)$. The results revealed that in the treatment of gingival recessions the use of different biomaterial group (other than amnion membrane) caused a reduction in $\mathrm{PD}$ when added to CAF (Fig. 2D). No significant difference was found for CTG, PRF, and collagen group as per subgroup analysis.

Table 1: General information of included studies

\begin{tabular}{|c|c|c|c|c|c|c|c|}
\hline \multirow[b]{2}{*}{ Author } & \multirow{2}{*}{$\begin{array}{l}\text { Publication } \\
\text { year/place }\end{array}$} & \multirow[b]{2}{*}{ Journal } & \multirow[b]{2}{*}{ Age range } & \multirow[b]{2}{*}{ Gender } & \multirow[b]{2}{*}{ Follow-up } & \multicolumn{2}{|c|}{ Intervention } \\
\hline & & & & & & Test & Control \\
\hline $\begin{array}{l}\text { Ghahroudi } \\
\text { et al. }{ }^{23}\end{array}$ & 2014/Iran & $\begin{array}{l}\text { International } \\
\text { Academy of } \\
\text { Periodontology }\end{array}$ & Above 18 years & $\begin{array}{l}\text { Male-30 } \\
\text { Female-41 }\end{array}$ & 3,6 months & $\begin{array}{l}\text { CAF+ amnion } \\
\text { membrane }\end{array}$ & $\mathrm{CAF}+\mathrm{CTG}$ \\
\hline $\begin{array}{l}\text { Chakraborthy } \\
\text { et al. }{ }^{24}\end{array}$ & 2015/India & $\begin{array}{l}\text { Journal of Clinical } \\
\text { and Diagnostic } \\
\text { Research }\end{array}$ & $\begin{array}{l}33.5 \pm 6.89 \\
\text { years }\end{array}$ & Not specified & 1, 3, 6 months & $\begin{array}{l}\text { CAF+ amnion } \\
\text { membrane }\end{array}$ & $\begin{array}{l}\text { CAF+ chorion } \\
\text { membrane }\end{array}$ \\
\hline Lafzi et al. ${ }^{25}$ & 2016/Iran & $\begin{array}{l}\text { Journal of Dental } \\
\text { Restorative, Dental } \\
\text { Clinics, Dental } \\
\text { Prospects }\end{array}$ & $34 \pm 12$ years & Not specified & $1,3,6$ months & $\begin{array}{l}\text { CAF+ amnion } \\
\text { membrane }\end{array}$ & $\mathrm{CAF}+\mathrm{CTG}$ \\
\hline Agarwal et al. ${ }^{26}$ & 2016/India & $\begin{array}{l}\text { European Journal of } \\
\text { Dentistry }\end{array}$ & Not specified & $\begin{array}{l}\text { Males-18, } \\
\text { Females-5 }\end{array}$ & 3,6 months & $\begin{array}{l}\text { CAF+ amnion } \\
\text { membrane }\end{array}$ & $\begin{array}{l}\text { CAF+ PRF and } \\
\text { CAF alone }\end{array}$ \\
\hline Jain et al. ${ }^{27}$ & 2017/India & $\begin{array}{l}\text { Journal of Clinical } \\
\text { and Diagnostic } \\
\text { Research }\end{array}$ & $18-55$ & $\begin{array}{l}\text { Males-15, } \\
\text { Females-15 }\end{array}$ & 3,6 months & $\begin{array}{l}\text { CAF+ } \\
\text { dehydrated } \\
\text { amnion } \\
\text { membrane }\end{array}$ & $\mathrm{CAF}+\mathrm{PRF}$ \\
\hline Mahajan et al. ${ }^{28}$ & 2018/India & $\begin{array}{l}\text { Journal of In- } \\
\text { dian society of } \\
\text { periodontology }\end{array}$ & $18-40$ & $\begin{array}{l}\text { Males-5, } \\
\text { Females-7 }\end{array}$ & 3,6 months & $\begin{array}{l}\text { CAF+ amnion } \\
\text { membrane }\end{array}$ & $\begin{array}{l}\text { CAF+ collagen } \\
\text { membrane }\end{array}$ \\
\hline Rehan et al. ${ }^{5}$ & 2018/India & $\begin{array}{l}\text { Contemporary } \\
\text { Clinical Dentistry }\end{array}$ & $20-45$ years & Males-10 & 6,18 months & $\begin{array}{l}\text { CAF+ amnion } \\
\text { membrane }\end{array}$ & $C A F+P R F$ \\
\hline
\end{tabular}


Table 2: Data of included studies

\begin{tabular}{|c|c|c|c|c|c|c|c|}
\hline Reference (year) & $\begin{array}{l}\text { MD in RD be- } \\
\text { tween baseline } \\
\text { and } 6 \text { months } \\
\text { follow-up }(\mathrm{mm})\end{array}$ & $\begin{array}{l}\text { MD in RW be- } \\
\text { tween baseline } \\
\text { and } 6 \text { months } \\
\text { follow-up }(\mathrm{mm})\end{array}$ & $\begin{array}{l}\text { MD in WKG be- } \\
\text { tween baseline } \\
\text { and } 6 \text { months } \\
\text { follow-up }(\mathrm{mm})\end{array}$ & $\begin{array}{l}\text { MD in PD be- } \\
\text { tween baseline } \\
\text { and } 6 \text { months } \\
\text { follow-up }(\mathrm{mm})\end{array}$ & $\begin{array}{l}\text { MD in CAL be- } \\
\text { tween baseline } \\
\text { and } 6 \text { months } \\
\text { follow-up }(\mathrm{mm})\end{array}$ & $\begin{array}{l}\text { MD in gingival } \\
\text { biotype between } \\
\text { baseline and } 6 \\
\text { months follow- } \\
\text { up }(\mathrm{mm})\end{array}$ & Other outcome \\
\hline \multirow[t]{2}{*}{$\begin{array}{l}\text { Ghahroudi et al. } \\
\text { (2014) }\end{array}$} & $2.4 \pm 1.654$ & $1.5 \pm 1.739$ & NR & NR & $2.4 \pm 1.40$ & $0.8 \pm 1.57$ & $\begin{array}{l}\text { Papilla dimen- } \\
\text { sion }\end{array}$ \\
\hline & $2.3 \pm 1.594$ & $2.7 \pm 1.561$ & NR & NR & $2.2 \pm 1.892$ & $1 \pm 1.39$ & \\
\hline \multirow[t]{2}{*}{$\begin{array}{l}\text { Chakraborthy } \\
\text { et al. (2015) }\end{array}$} & $1.56 \pm 0.68$ & $2.17 \pm 0.58$ & $1.42 \pm 0.51$ & NR & NR & NR & $\begin{array}{l}\mathrm{Pl}, \mathrm{Gl}, \mathrm{RAL}, \% \\
\text { root coverage }\end{array}$ \\
\hline & $2.00 \pm 0.85$ & $2.50 \pm 1.17$ & $1.00 \pm 0.51$ & NR & NR & NR & \\
\hline \multirow[t]{2}{*}{$\begin{array}{l}\text { Lafzi et al. } \\
(2016)\end{array}$} & $2.1 \pm 1.12$ & $2.7 \pm 1.45$ & $0.11 \pm 0.3$ & $0.15 \pm 0.35$ & $2.14 \pm 1.29$ & NR & $\begin{array}{l}\% \text { root cover- } \\
\text { age }\end{array}$ \\
\hline & $2.1 \pm 1.13$ & $2.7 \pm 1.46$ & $0.11 \pm 0.4$ & $0.15 \pm 0.36$ & $2.14 \pm 1.30$ & NR & \\
\hline \multirow[t]{2}{*}{$\begin{array}{l}\text { Agarwal et al. } \\
(2016)\end{array}$} & $0.7 \pm 1.23$ & $1.5 \pm 1.28$ & $0.99 \pm 1.56$ & $0.1 \pm 0.98$ & $1.2 \pm 1.39$ & $-0.01 \pm 0.15$ & $\begin{array}{l}\text { PI, GI, AG, PCS, } \\
\text { PES, HS }\end{array}$ \\
\hline & $1.5 \pm 0.99$ & $1.8 \pm 1.79$ & $1.4 \pm 1.56$ & $0.3 \pm 0.79$ & $1.52 \pm 1.73$ & $-0.07 \pm 0.13$ & \\
\hline \multirow[t]{2}{*}{ Jain et al. (2017) } & $1.81 \pm 0.97$ & NR & $0.69 \pm 0.60$ & NR & NR & NR & PI \\
\hline & $1.34 \pm 0.77$ & NR & $0.55 \pm 0.72$ & NR & NR & NR & \\
\hline \multirow{2}{*}{$\begin{array}{l}\text { Mahajan et al. } \\
(2018)\end{array}$} & $2.33 \pm 0.86$ & NR & NR & $0.2 \pm 0.33$ & $2.45 \pm 0.89$ & $-0.63 \pm 0.13$ & $\mathrm{Pl}, \mathrm{Gl}$ \\
\hline & $1.83 \pm 0.91$ & NR & NR & $0.25 \pm 0.54$ & $2.20 \pm 1.19$ & $-1.49 \pm 0.14$ & \\
\hline \multirow{2}{*}{$\begin{array}{l}\text { Rehan et al. } \\
\text { (2018) }\end{array}$} & $1.80 \pm 0.92$ & $0.30 \pm 0.48$ & $1.10 \pm 1.10$ & $0.20 \pm 0.63$ & $1.50 \pm 1.35$ & $-0.20 \pm 0.42$ & \\
\hline & $1.50 \pm 1.53$ & $0.20 \pm 0.42$ & $0.80 \pm 1.03$ & $0.30 \pm 1.34$ & $1.00 \pm 1.05$ & $-0.20 \pm 0.42$ & \\
\hline
\end{tabular}

\section{CAL Reduction}

The meta-analysis was performed in five studies. Two studies ${ }^{24,27}$ were excluded as they provided incomplete data. A fixed-effects model was employed $\left(I^{2}=0 \%\right)$ since there was no reported heterogeneity. The results exhibited that in the treatment of gingival recessions the use of different biomaterial groups (other than amnion membrane) caused a gain of CAL when added to CAF (Fig. 2E). No significant difference was found for CTG, PRF, and collagen group as per subgroup analysis.

\section{GT Gain}

Three studies ${ }^{24,25,27}$ out of seven were excluded from meta-analysis as there was incomplete data. As the heterogeneity was high $\left(I^{2}=98.4 \%\right)$ a random-effect model was employed. According to the results of our meta-analysis different biomaterial groups other than amnion (Fig. 2F) achieved a greater GT gain. Subgroup analysis exhibited significant difference for collagen membrane group, with an MD of $0.86 \mathrm{~mm}(95 \% \mathrm{Cl}: 0.75-0.97 \mathrm{~mm} ; p<0.00001)$ but for the CTG and PRF groups, no significant difference was intimated.

\section{Discussion}

Ever since CAF was introduced by Norberg in 1926 researchers have done enormous work to achieve predictable, less invasive, and effective outcomes from this surgical procedure. But in the case of CAF, many surgical defects regenerate incompletely since the formation of long junctional epithelium occurs by an invasion of the epithelial cell into the defect which plays a vital role in repair and not regeneration. ${ }^{32}$ So, the technique based on the GTR principle is used where CAF is combined with different biomaterials like PRF, amnion, chorion, collagen, and ADM which act as a barrier membrane so as to improve the result. ${ }^{33}$
Amnion membrane has shown exceptional biocompatibility, good healing capacity with easy availability at an affordable cost having a good shelf life. Moreover, to a great extent, it resembles the basement membrane of human oral mucosa, ${ }^{34,35}$ so this membrane have been suited for the treatment of different periodontal conditions like furcation defects, ${ }^{36}$ intrabony defects, ${ }^{37}$ and gingival recession. The clinical evidence was insufficient to conform reconfil the effect of amnion membrane, so this review was intended to compare the effectiveness of amnion membrane with CAF in the treatment of gingival recession in adult patients.

Only RCTs were scrutinized for this systematic review; to avoid serious methodological flaws and to get stronger evidence for the systematic review. Miller's Class I and II gingival recession shows the highest success rates for root coverage procedures. ${ }^{38}$ So, the studies with the patients diagnosed with chronic periodontitis and having Miller's Class I and II recession were only included. Smokers were eliminated in all studies as they negatively influence CAL gain and gingival recession reduction. ${ }^{39}$

Regarding the outcome, there is an equal effect by both the groups for the $\mathrm{RD}$ reduction. But in the case of $\mathrm{RW}$ reduction, the results were in favor of amnion membrane with CAF group but the difference was not statistically significant. Heterogeneity of RW seems to be linked to the different surgical techniques like in Agarwal et al.'s ${ }^{26}$ study microsurgical protocol was used, in Lafzi et al.'s ${ }^{25}$ study, only partial-thickness flap was elevated, in Chakraborthy et al.'s ${ }^{24}$ study root biomodification with EDTA was performed whereas in Ghahroudi et al.'s ${ }^{23}$ study tetracycline was applied for 2 minutes over the exposed root surface. In terms of $\mathrm{PD}$ reduction, CAL gain, KWT, and GT gain different biomaterial (CTG, PRF, and collagen) exhibited effective results along with CAF but the difference was not statistically significant. Heterogeneity in GT seems to be because of different technique employed for 

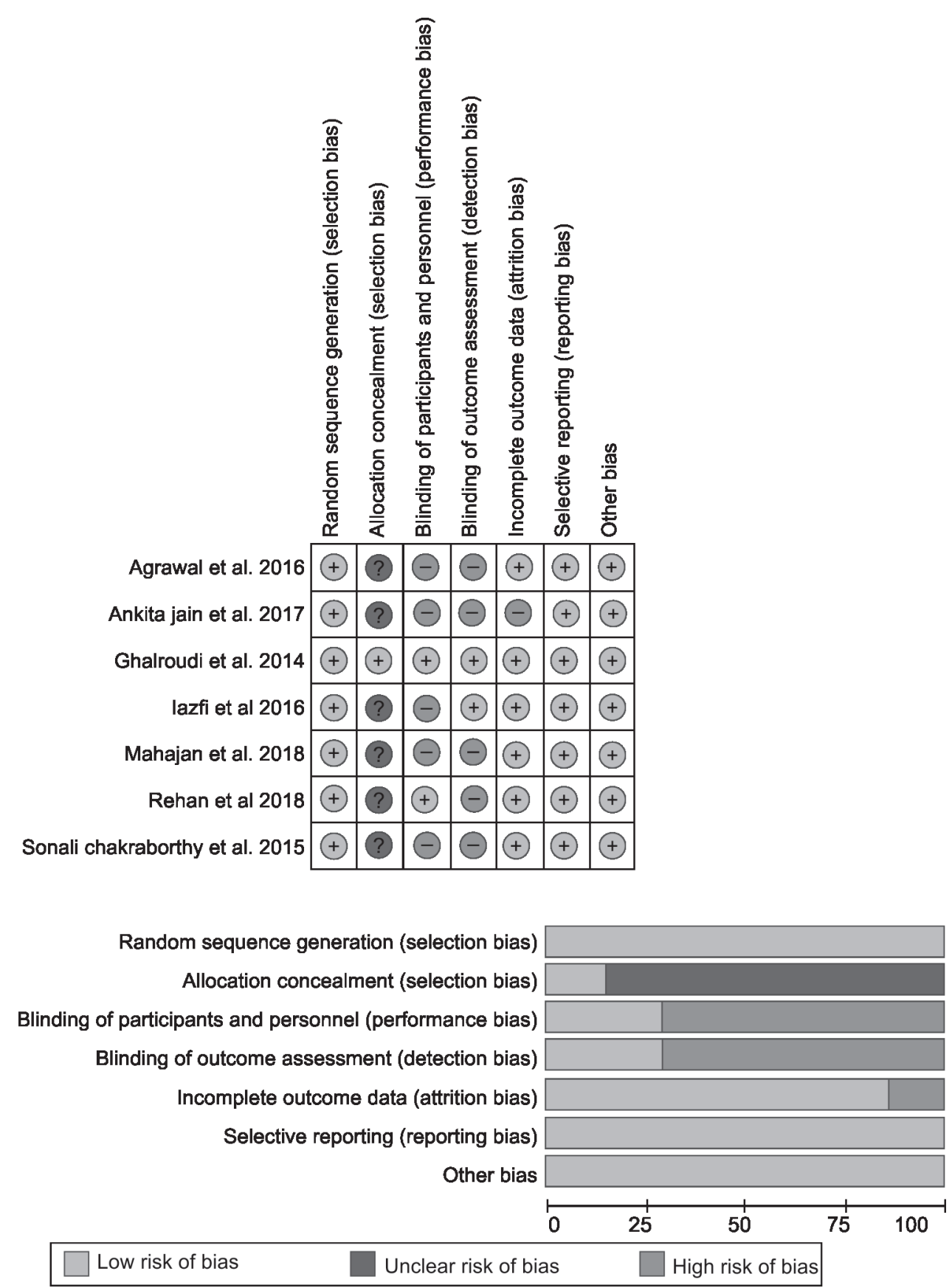

Fig. 1: Risk of bias summary of the included studies

measurement of GT in different studies. Gain in CAL suggests periodontal regeneration, new attachment or reattachment but due to the lack of histological evidence in all of the included study the actual phenomenon behind gain in clinical attachment level cannot be explained. ${ }^{28}$

For KWT gain, statistically significant difference was found in the study where chorion membrane was used along with CAF which was similar to the result found in Sharma et al.'s ${ }^{17}$ study.

GT gain in the collagen membrane group demonstrated a statistically significant difference which is attributed due to the thickness of the amnion membrane is around $300 \mathrm{~nm}$ in crosssection, unlike collagen membrane which averages around
$750 \mathrm{~nm} \cdot{ }^{40}$ Degradation of collagen membrane is slow it takes around 6-8 weeks. Space created by the barrier membranes with clot formation leads to cellular proliferation and migration which may be responsible to increase the thickness of the gingival biotype. Later as the barrier membrane is degraded by the host enzymes secondary space is created which further increases the thickness of the gingival tissue. ${ }^{28}$ The results observed were similar to the findings of Cardaropoli and Cardaropoli. ${ }^{41}$

It is important to consider that the results may be affected significantly by other factors also such as flap tension, soft tissue thickness, and experience of the operator. 


\section{CONCLUSION}

Thus, within the limitation of the study, it seems that the amnion membrane can be used successfully along with CAF for the treatment of gingival recession.
But only a tentative conclusion can be drawn from this study since there is a limited number of studies with restricted data, a follow-up period of short duration, and having a comparatively high risk of bias. Hence, higher quality RCTs with longer follow-up and substantial sample size are needed to draw a definitive conclusion.

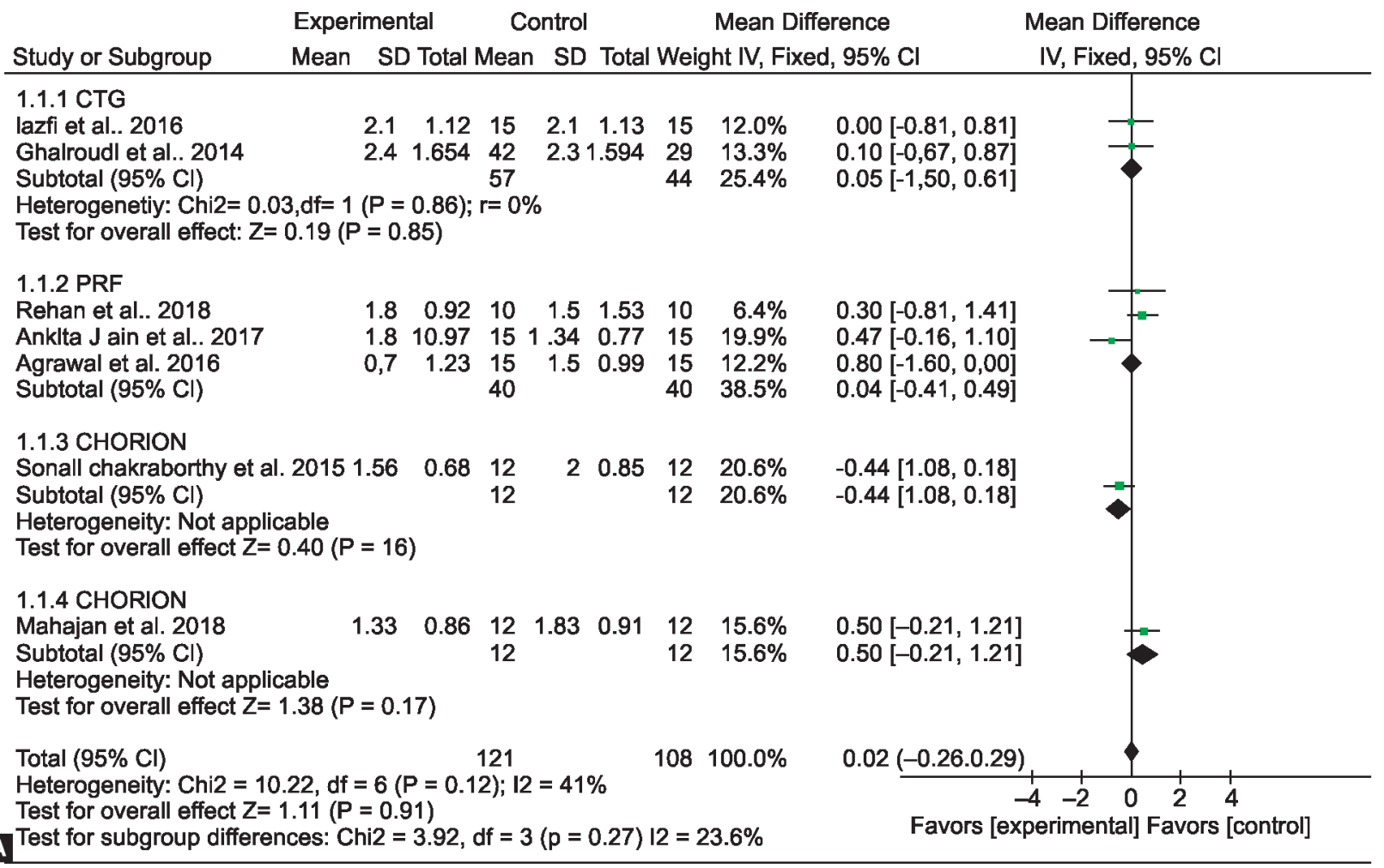

\begin{tabular}{|c|c|c|c|c|}
\hline & Experime & Control & Mean Difference & Mean Difference \\
\hline Study or Subgroup & Mean & SD Total Mean & SD Total Weight IV, Fixed, $95 \% \mathrm{Cl}$ & IV, Fixed, 95\% Cl \\
\hline
\end{tabular}
1.2.1 CTG

Ghalroudl et al. 2014

lazfi et al. 2016

Subtotal $(95 \% \mathrm{Cl})$

$\begin{array}{rrrrrrr}1.5 & 1.739 & 42 & 2.7 & 1.561 & 29 & 20.1 \% \\ 2.7 & 1.45 & 15 & 2.7 & 1.46 & 15 & 14.5 \% \\ & & 57 & & & 44 & 34.5 \%\end{array}$

Heterogenetiy: Tau2 $=0.50$, Chi2 $=3.29$, df $=1(P=0.07) ; 12=70 \%$

Test for overall effect: $Z=0.09(P=0.27)$

1.2.2 PRF

Agrawal et al. 2016

Rehan et al. 2018

Subtotal $(95 \% \mathrm{Cl})$

Heterogenetiy: Tau2 $=0.00$, Chi2 $=0.44, \mathrm{df}=1(\mathrm{P}=0.51) ; 12=0 \%$

$\begin{array}{rrrrrrr}1.5 & 1.28 & 15 & 1.8 & 1.79 & 15 & 13.3 \% \\ 0.2 & 0.48 & 10 & 002 & 0.42 & 10 & 31.0 \% \\ & & 25 & & & 25 & 44.4 \%\end{array}$

Test for overall effect: $Z=0.29(P=0.77)$

1.2.3 CHORION

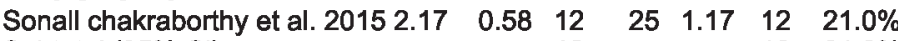

Subtotal $(95 \% \mathrm{Cl})$

Heterogeneity: Not applicable

Test for overall effect $Z=0.89(P=0.38)$

Total $(95 \% \mathrm{Cl})$

Heterogeneity: Tau2 = 0.17, Chi2 = 8.91, df = $4(P=0.06) ; \mathrm{I} 2=55 \%$

Test for overall effect $Z=1.25(P=0.21)$

B Test for subgroup differences: Chi2 $=1.86, d f=2(p=0.39) \mid 2=0 \%$
$-1.20[-1,97,0.43]$

$0.00[-0.84,0.04]$

$0.65[-1,82,0.52]$

IV, Fixed, $95 \% \mathrm{Cl}$
$-0.30[-1.41,0,81]$

$0.10[-0.30,0.50]$

$0.06[-6.32,0.43]$

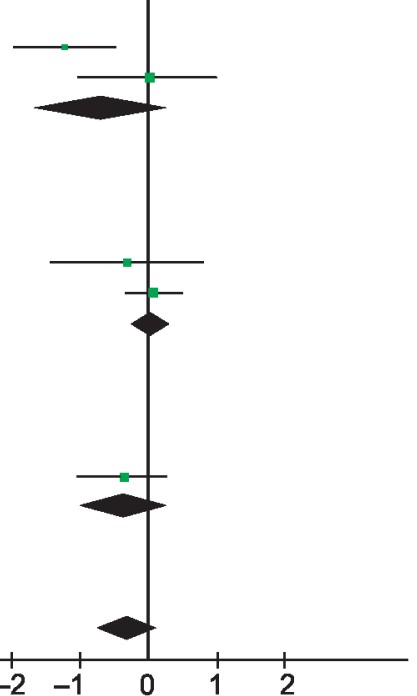
Favors [experimental] Favors [control] 


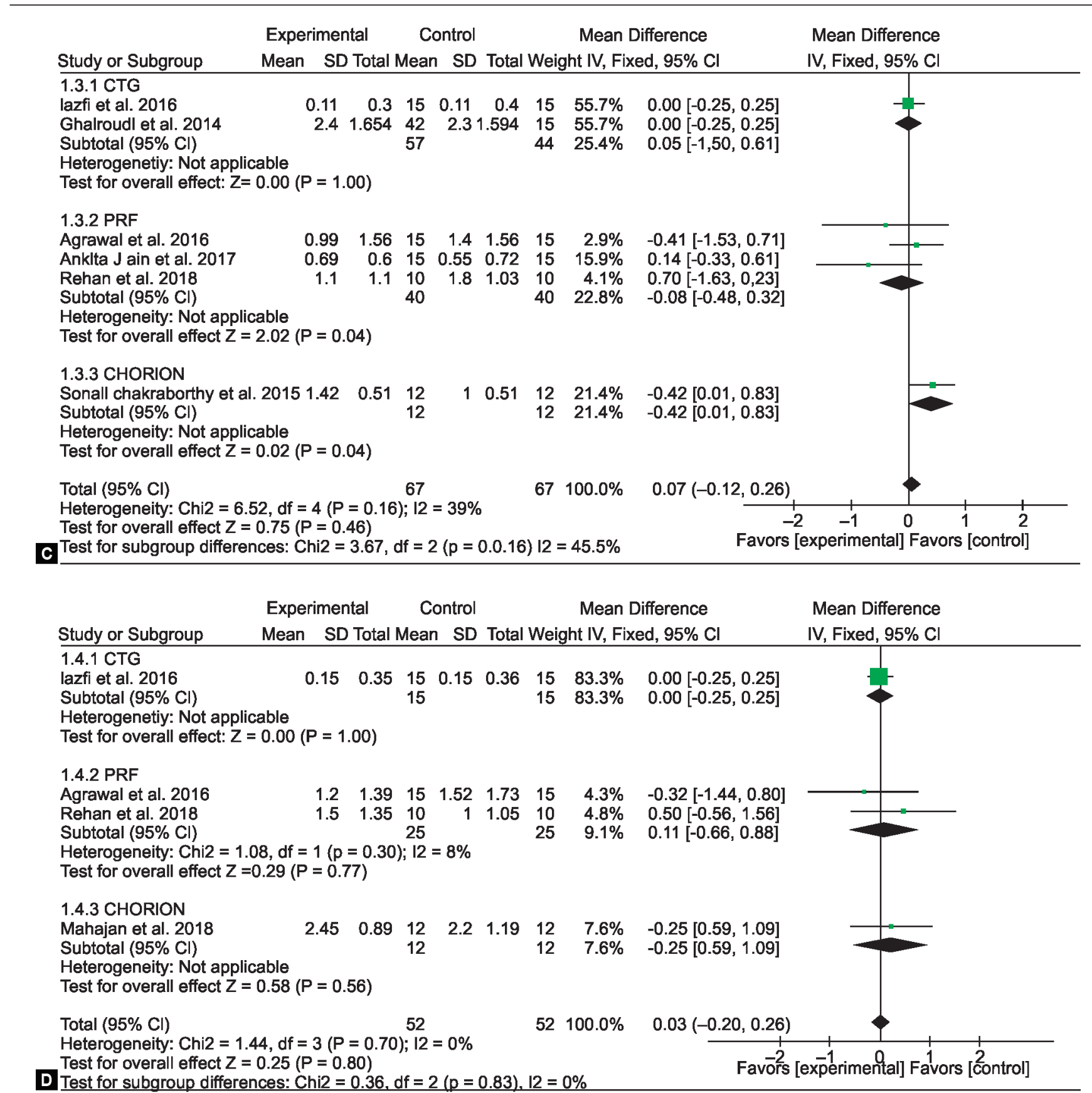

Test for overall effect $Z=0.25(P=0.80)$

Test for subgroup differences: Chi2 $=0.36, d f=2(p=0.83), 12=0 \%$ 


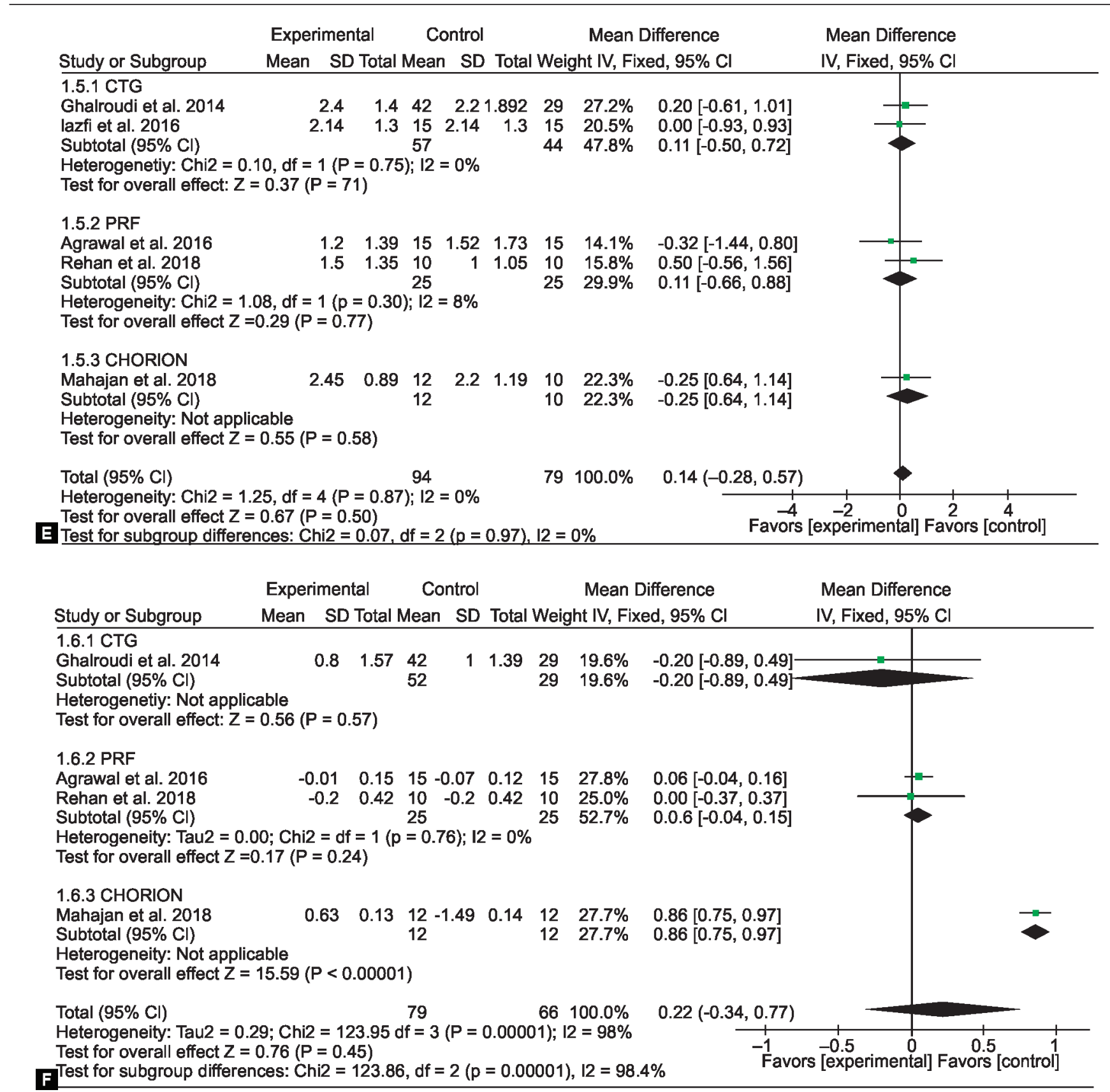

Figs 2A and F: (A) Forest plot for RD reduction; (B) RW reduction; (C) Forest plot for WKG gain; (D) PD reduction; (E) Forest plot for CAL reduction; (F) GT gain 


\section{References}

1. Zucchelli G, Mounssif I. Periodontal plastic surgery. Periodontol2000 2015;68(1):333-368. DOI: 10.1111/prd.12059.

2. Daprile G, Gatto MR, Checchi L. The evolution of buccal gingival recessions in a student population: a 5-year follow-up. J Periodontol 2007;78(4):611-614. DOI: 10.1902/jop.2007.060277.

3. Serino G, Wennström JL, Lindhe J, et al. The prevalence and distribution of gingival recession in subjects with a high standard of oral hygiene. J Clin Periodontol 1994;21(1):57-63. DOI: 10.1111/j.1600051x.1994.tb00278.x.

4. Kassab MM, Cohen RE. The etiology and prevalence of gingival recession. J Am Dent Assoc 2003;134(2):220-225. DOI: 10.14219/jada. archive.2003.0137.

5. Rehan $M$, Khatri $M$, Bansal $M$, et al. Comparative evaluation of coronally advanced falp using amniotic membrane and platelet-rich fbrin membrane in gingival recession: an 18-month clinical study, Contemp Clin Dentis 2018;9(2):188-194. DOI: 10.4103/ccd.ccd_799_17.

6. McGuire MK, Cochran DL. Evaluation of human recession defects treated with coronally advanced faps and either enamel matrix derivative or connective tissue. Part 2: histological evaluation. J Periodontol 2003;74(8):1126-1135. DOI: 10.1902/jop.2003.74. 8.1126.

7. Aroca S, Keglevich T, Barbieri B, et al. Clinical evaluation of a modified coronally advanced flap alone or in combination with a platelet-rich fibrin membrane for the treatment of adjacent multiple gingival recessions: a 6-month study. J Periodontol 2009;80(2):244-252. DOI: 10.1902/jop.2009.080253.

8. Zuhr O, Bäumer D, Hürzeler M. The addition of soft tissue replacement grafts in plastic periodontal and implant surgery: critical elements in design and execution. J Clin Periodontol 2014;41(Suppl. 15):S123S142. DOI: 10.1111/jcpe.12185.

9. Aroca S, Keglevich T, Nikolidakis D, et al. Treatmentof class III multiple gingival recessions: a randomized clinical trial. J Clin Periodontol 2010;37(1):88-97. DOI: 10.1111/j.1600-051X.2009.01492.x.

10. Modaressi $M$, Wang HL. Tunneling procedure for root coverage using acellular dermal matrix: a case series. Int J Periodont Restorat Dent 2009;29(4):395-403.

11. Esteves J, Bhat KM, Thomas B, et al. Efficacy of human chorion membrane allograft for recession coverage: a case series. J Periodontol 2015;86(8):941-944. DOI: 10.1902/jop.2014.140025c.

12. Shieh AT, Wang HL, O'Neal R, et al. Development and clinical evaluation of a root coverage procedure using a collagen barrier membrane. J Periodontol 1997;68(8):770-778. DOI: 10.1902/ jop.1997.68.8.770.

13. Singh $H$, Singh $H$. Bioactive amnion as a guided tissue regeneration (GTR) membrane for treatment of isolated gingival recession. A case report. Indian J Dentis 2013;4(2):110-113. DOI: 10.1016/j. ijd.2012.12.007.

14. Niknejad H, Peirovi $H$, Jorjani $M$, et al. Properties of the amniotic membrane for potential use in tissue engineering. Eur Cell Mater 2008;15:88-99. DOI: 10.22203/ecm.v015a07.

15. Rana MP, Mehrotra N. Human amniotic membrane: hope in periodontal regeneration. Int J Sci Res (IJSR) 2016;5(4):564-569. DOI: 10.21275/v5i4.NOV162635.

16. Mishra S, Singh S. Human amniotic membrane: can it be a ray of hope in periodontal regeneration? Indian J Res 2014;3(9):118-121.

17. Sharma A, Komal Y. Amniotic membrane-a novel material for the root coverage: a case series. J Indian Soc Periodontol 2015;19(4):444-448. DOI: 10.4103/0972-124X.154166.

18. Liberati A, Altman DG, Tetzlaff J, et al. The PRISMA statement for reporting systematic reviews and meta-analyses of studies that evaluate health care interventions: explanation and elaboration. J Clin Epidemiol 2009;62(10):e1-e34. DOI: 10.1016/j.jclinepi.2009.06.006.

19. Moher D, Shamseer L, Clarke M, et al. Preferred reporting items for systematic review and meta-analysis protocols (PRISMA-P) 2015 statement. Syst Rev 2015;4(1):1. DOI: 10.1186/2046-4053-4-1.
20. Higgins J, Cochrane Handbook for Systematic Reviews of Interventions. Version 5.1. 0. The Cochrane Collaboration; 2011. Available from: http://www.cochrane-handbook.org.

21. Manager RR, The Nordic Cochrane Centre, the CochraneCollaboration. Version 5.3. Copenhagen: Computer Program; 2014.

22. Cheng GL, Fu E, Tu YK, et al. Root coverage by coronally advanced flap with connective tissue graft and/or enamel matrix derivative: a meta-analysis. J Period Res 2015;50(2):220-230. DOI: 10.1111/jre.12199.

23. Ghahroudi AA, Khorsand A, Rokn AR, et al. Comparison of amnion allograft with connective tissue graft for root coverage procedures: a double-blind, randomized, controlled clinical trial. J Int Acad Periodontol 2013;15(4):101.

24. Chakraborthy S, Sambashivaiah S, Kulal R, et al. Amnion and chorion allografts in combination with coronally advanced flap in the treatment of gingival recession: a clinical study. J Clin Diagnos Re 2015;9(9):ZC98. DOI: 10.7860/JCDR/2015/12971.6572.

25. Lafzi A, Abolfazli N, Faramarzi M, et al. Clinical comparison of coronally-advanced flap plus amniotic membrane or subepithelial connective tissue in the treatment of Miller's class I and II gingival recessions: a split-mouth study. J Dent Res, Dent Clin, Dent Prosp 2016;10(3):162. DOI: 10.15171/joddd.2016.026.

26. Agarwal SK, Jhingran R, Bains VK, et al. Patient-centered evaluation of microsurgical management of gingival recession using coronally advanced flap with platelet-rich fibrin or amnion membrane: a comparative analysis. Eur J Dentis 2016;10(1):121. DOI: 10.4103/13057456.175686 .

27. Jain A, Jaiswal GR, Kumathalli $K$, et al. Comparative evaluation of platelet rich fibrin and dehydrated amniotic membrane for the treatment of gingival recession-a clinical study. J Clin Diagnos Res 2017;11(8):ZC24. DOI: 10.7860/JCDR/2017/29599.10362.

28. Mahajan R, Khinda P, Shewale A, et al. Comparative efficacy of placental membrane and Healiguide ${ }^{\mathrm{TM}}$ in treatment of gingival recession using guided tissue regeneration. J Indian Soc Periodontol 2018;22(6):513. DOI: 10.4103/jisp.jisp_88_18.

29. Chopra P, Kassal J, Masamatti SS, et al. Comparative evaluation of clinical efficacy of coronally advanced flap alone and in combination with placental membrane and demineralized freeze-dried bone allograft in the treatment of gingival recession. J Indian Soc Periodontol 2019;23(2):13. DOI: 10.4103/jisp.jisp_308_18.

30. Irfan M, Mehta T, Kumar S, et al. Comparative clinical study of coronally positioned flap with and without dehydrated amnion allograft in the treatment of gingival recession. J Dent Health Oral Disord Ther 2017;8(3):00281. DOI: 10.15406/jdhodt.2017.08.00281.

31. George SG, Kanakamedala AK, Mahendra J, et al. Treatment of gingival recession using a coronally-advanced flap procedure with or without placental membrane. J Investigat Clin Dentis 2018;9(3):e12340. DOI: 10.1111/jicd.12340.

32. Blumenthal NM. The use of collagen membranes to guide regeneration of new connective tissue attachment in dogs. J Periodontol 1988;59(12):830-836. DOI: 10.1902/jop.1988.59.12.830.

33. Wang HL, Al-Shammari KF. Guided tissue regeneration--based root coverage utilizing collagen membranes: technique and case reports. Quintessence Int 2002;33(10):715-721.

34. Pakkala T, Virtanen I, Oksanen J, et al. Function of laminins and laminin-binding integrins in gingival epithelial cell adhesion. J Periodontol 2002;40(7):709-719. DOI: 10.1902/jop.2002.73.7.709.

35. Takashima S, Yasuo M, Sanzen N, et al. Characterization of laminin isoforms in human amnion. Tissue and Cell 2008;40(2):75-81. DOI: 10.1016/j.tice.2007.09.001.

36. Kaur J, Bathla SC. Regenerative potential of autologous plateletrich fibrin with and without amnion membrane in the treatment of grade-II furcation defects: a clinicoradiographic study. J Indian Soc Periodontol 2018;22(3):235. DOI: 10.4103/jisp.jisp_119_18.

37. Kiani YF, Moloudi F, Nozari HB, Comparison of amnion membrane with Bio-Gide in conjunction with Bio-Oss in treatment of intrabony periodontal defects. Sadra Medical Sciences Journal 2013;1(4):215-232 
38. Alghamdi $\mathrm{H}$, Babay $\mathrm{N}$, Sukumaran $\mathrm{A}$. Surgical management of gingival recession: a clinical update. Saudi Dent J 2009;21(2):83-94. DOI: 10.1016/j.sdentj.2009.07.006.

39. Chambrone L, Chambrone D, Pustiglioni FE, et al. The influence of tobacco smoking on the outcomes achieved by root-coverage procedures: a systematic review. J Am Dent Associat 2009;140(3):294306. DOI: 10.14219/jada.archive.2009.0158.
40. Chopra A, Thomas BS. Amniotic membrane: a novel material for regeneration and repair. J Biomim Biomater Tissue Eng 2013; 18:106.

41. Cardaropoli D, Cardaropoli G. Healing of gingival recessions using a collagen membrane with a hemineralized xenograft: a randomized controlled clinical trial. Int J Periodontics Restorative Dent 2009;29(1):59-67. 